\title{
Enumeration and Molecular Characterization of Circulating Tumour Cells in Endometrial Cancer
}

Lemech $\mathrm{CR}^{12}$, Ensell $\mathrm{L}^{1}$, Paterson $\mathrm{JC}^{1}$, Eminowicz $\mathrm{G}^{1}$, Lowe $\mathrm{H}^{1}$, Arora $\mathrm{R}^{1}$, Arkenau $\mathrm{HT}^{1}{ }^{2}$, Widschwendter $\mathrm{M}^{1}$, MacDonald $\mathrm{N}^{1}$, Olaitan $\mathrm{A}^{1}$, Mould $\mathrm{T}^{1}$, Meyer $\mathrm{T}^{1}$, Hartley $\mathrm{J}^{1}$, Mitra $\mathrm{A}^{1}$, Ledermann $\mathrm{A}^{1}$, McCormack $\mathrm{M}^{1}$, Kristeleit RS'

${ }^{1}$ University College London Hospital and UCL Cancer Institute

${ }^{2}$ Sarah Cannon Research Institute, UK

\section{Short Title: CTCs in EC}

\section{Corresponding author}

Dr Charlotte R Lemech

Prince of Wales Clinical School, Faculty of Medicine

UNSW, Sydney, NSW, 2052, Australia

Phone number: +61 29382 8823; (mob) +61 405284009

Fax: +61293828885

Email address: c.lemech@unsw.edu.au

Keywords: circulating tumour cells, endometrial cancer, stathmin, CellSearch, EpCAM 


\section{Abstract}

BACKGROUND: This is a feasibility study to determine whether circulating tumour cells (CTCS) are detectable and suitable for molecular profiling in advanced endometrial cancer (aEC).

METHOD: Between October 2012 and February 2014, 30 patients with aEC had baseline and up to 3 follow-up samples. CTCs and stathmin expression were evaluated using the CellSearch platform. EPCAM and stathmin immunohistochemistry were performed on FFPE tumour tissue.

RESULTS: 18 from 30 (60\%) patients had detectable CTCs during study [1 CTC ( $n=7), 2(n=4), 3(n=1)$, $4(n=2), 7(n=1), 8(n=1), 22(n=1), 172(n=1)$ in $7.5 \mathrm{ml}$ blood]. 10 from 18 patients had between 50$100 \%$ of detectable CTCs that were stathmin positive. More CTC positive than CTC negative patients had non-endometrioid vs endometrioid histology, tumour size $\geq 5 \mathrm{~cm}$ vs $<5 \mathrm{~cm}$, higher stage disease and worse survival [Hazard Ratio 3.3, p>0.05, 95\% Cl 0.7-16.2]. 21 tumour blocks were tested for EpCAM and stathmin IHC. Stathmin tumour immunostaining scores (TIS) on IHC were higher in CTC+ patients.

CONCLUSION: CTC enumeration and molecular profiling with stathmin on the CellSearch platform is feasible in aEC. Stathmin TIS on IHC, a known prognostic marker in EC, was associated with CTC positivity. 


\section{Introduction}

Despite being the most common gynaecological malignancy in the developed world and $4^{\text {th }}$ most common women's cancer in the UK [1], endometrial cancer (EC) treatment is limited to standard chemotherapy with no approved molecularly targeted therapies. Although $75 \%$ of patients present with surgically resectable early stage disease, those with regional and distant metastases have poor outcomes and limited treatment options. The currently used prognostic and predictive parameters that guide patient management in EC are based on historical clinicopathologic factors, without correlation with molecular aberrations.

CTCs are cancer cells known to circulate in the peripheral blood of cancer patients and are not detected in healthy individuals [2]. As CTCs can be analysed from a simple blood draw, their use for prognostic and predictive purposes and to assess drug response and resistance is appealing. Novel technologies also allow molecular characterisation on CTCs that could assist with treatment selection and identify changes in the molecular profile of an individual's tumour over time [3-6]. Numerous techniques for the isolation and enumeration of CTCs have been reported, but only the CellSearch (Janssen) method is analytically validated and FDA approved for use for prostate, breast and colorectal cancers $[7,8][9]$. CellSearch relies on detection of epithelial cell adhesion molecule (EpCAM), which has a reported high expression in EC of $65-80 \%$ across all grades and stages [10]. As such, we investigated whether CTCs were present and could be enumerated in patients with advanced EC.

Within the CellSearch system, there is a fourth channel in which a fluorescein-conjugated antibody of interest, stathmin in this study, can be analysed along with routine CTC morphological and staining features. Stathmin is a cytosolic phosphoprotein and regulator of the microtubule cytoskeleton and cell cycle [11] and is also a highly relevant biomarker in EC [12], with overexpression demonstrated in between $27-57 \%$ [12]. It has prognostic significance in several malignancies, including EC [13-22] and there is evidence for its prognostic and predictive value for metastases $[12,21]$ and response to taxane chemotherapy [20,23-25]. There is also evidence for stathmin as a surrogate marker of phosphoinositide 3-kinase (PI3K) pathway activation [19], one of the most commonly aberrant pathways in EC, and is associated with phosphatase and tensin homologue (PTEN) loss and phosphatidylinositol-4,5-bisphosphate 3-kinase, catalytic subunit alpha (PIK3CA) amplification $[19,26]$. Thus, longitudinal assessment of stathmin expression may further establish its role as a predictive marker of PI3K activation and in monitoring response to PI3K inhibition. 
CTC enumeration and molecular profiling (MP), if feasible, may provide one of the first predictive biomarkers to monitor patients' treatment in EC and allow for longitudinal assessment of molecular changes to assist with targeted therapy development.

\section{Methods \\ Study Design}

Patients with histologically confirmed stage III and IV endometrioid (EEC) and non-endometrioid EC (NEEC) were eligible. Patients were greater than 18 years of age and assessed at any time point of their treatment, including before surgery, before and after radiotherapy or before, during and after chemotherapy. Exclusion criteria included prior history of another cancer within the last 5 years, except non-melanoma skin cancer. CTC enumeration was performed every 3-6 months or if there was a change in clinical status, with up to 4 samples taken per patient.

After local Research Ethics Committee and institutional approval, patients from University College London Hospitals (UCLH) and Sarah Cannon Research Institute UK (SCRI UK) participated between October 2012 and February 2014. All patients provided written informed consent.

For patients whose archival tumour tissue was held at UCLH histopathology department, EpCAM and stathmin immunohistochemistry (IHC) was performed. Clinical data including demographic, clinicopathologic information, details of treatment, disease recurrence and survival were retrieved from the UCLH and SCRI UK patient information systems.

\section{Isolation and enumeration of CTCs}

At each time point, a peripheral blood sample of up to $15 \mathrm{ml}(2 \times 7.5 \mathrm{ml})$ for CTC isolation and enumeration was collected in two CellSave Preservative tubes (Cat No 7900005) and maintained at room temperature. Each specimen was processed within 96 hours of being received at the UCL Cancer Institute by trained laboratory staff who were blinded as to the clinical status of each patient. Using the CellSearch CTC kit on the Celltracks Autoprep system, cells expressing EpCAM were immunomagnetically identified. Cells were then fluorescently labelled with 4'6-diamidino-2phenylindole (DAPI), cytokeratin 8, 18, 19-phycoerythrin (CK-PE) and CD45-allophycocyan (CD45APC) to identify nuclear, cytokeratin and leucocyte staining respectively. The CellTracks Analyzer II (Cat No 9555 RUO), a four-colour semi-automated fluorescence microscope, was then used for scanning and reconstruction of cellular images, which were reviewed by trained laboratory staff. CTCs were defined as positive for CK-PE and DAPI, negative for CD45-APC and having the correct morphology to be characterised as a tumour cell.

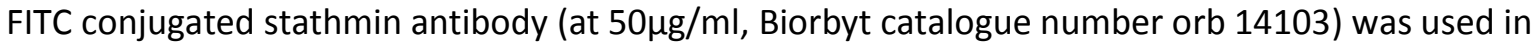
the fourth channel.

\section{FFPE Tissue Processing and IHC assessment}


For patients who had a biopsy or surgery performed at UCLH, EpCAM (1/4 dilution; mouse antihuman, RTU-ESA; Novocastra, Newcastle, UK) and stathmin (1/30 dilution; 3352 CellSignalling, Hertfordshire, UK) IHC was performed on the available FFPE tumour blocks.

Each archival tumour block was sectioned at 3 micron thickness onto charged slides, drained and baked at $60^{\circ} \mathrm{C}$ for 60 minutes. Unstained slides were labelled and placed for IHC staining of EpCAM and stathmin primary antibodies on the Leica Bond III autostainer platform, using the Bond Polymer Refine Detection Kit (Cat No DS9800).

The methodology and specific protocols for each primary antibody are outlined in the Supplementary Material.

The EpCAM and stathmin IHC analyses were interpreted with a consultant gynae-oncology histopathologist, who was blinded as to the CTC status of each patient. A Tumour Immunostaining Score (TIS) was generated, as previously published for both EpCAM and stathmin [12, 27, 28]. The TIS is a product of a proportion score and an intensity score. For EpCAM expression, the proportion score describes the estimated fraction of positively stained tumour cells (0: none; $1:<10 \% ; 2: 10-$ 50\%; 3: 51-80\%; 4: >80\%). The intensity score represents the estimated staining intensity as compared with a normal FFPE control (0: no staining; 1: weak; 2: moderate; 3 : strong). The TIS ranges from 0-12 and is classified into 4 subgroups as follows: no expression (TIS 0), weak (TIS 1-4), moderate (TIS 6 and 8) and intense expression (TIS 9 and 12) [28]. The stathmin TIS is also the product of staining intensity, scored as per the EPCAM scoring system, and the area of tumour with positive staining (0: no staining, $1:<10 \%, 2: 10-50 \%, 3:>50 \%$ of tumour cells). The range is $0-9$ [12] with moderate/intense expression as an index $\geq 4 / 9$ and absent/minimal expression as an index $<4$, with a high protein level defined as the upper quartile $[27,29]$, as has been previously reported [12, 27].

\section{Statistical Analysis}

Statistical analysis was performed using Stata, version 12.1. Kaplan Meier curves were generated for time to recurrence and overall survival. $p$-values less than 0.05 were considered statistically significant.

\section{Results}

A total of 35 patients were enrolled, of whom 3 did not meet the required eligibility criteria and 2 were not evaluable. The 3 ineligible patients had pre-operative CTC assessment performed based on staging as locally advanced EC and were then confirmed to have synchronous stage I endometrial and stage III or IV ovarian/primary peritoneal cancers. Of the 2 patients that were not evaluable, 1 consented but did not have a further blood test for CTC collection, and the other had a sample collected, but the CellSearch system malfunctioned at the time of analysis. 


\section{CTC enumeration}

The CTC results for the remaining 30 patients included 3 with locally advanced disease and 27 with metastatic disease. 18 of the 30 patients (60\%) were CTC positive (CTC+), all of whom had metastatic disease. 7 of these 18 patients (39\%) were positive for 1 CTC per $7.5 \mathrm{ml} \mathrm{blood,} 4$ (22\%) had 2 CTCs, 1 had 3 CTCs (5.6\%), 2 had 4 CTCs (11\%) and 1 each (5.6\%) had 7 CTCs, 8 CTCs, 22 CTCs and 172 CTCs per $7.5 \mathrm{ml}$ blood.

Differences in the clinical course at the time of CTC collection for the CTC+ and CTC- patients are outlined in Table 1. At the time of first CTC collection, all CTC+ patients had either newly diagnosed stage IV or recurrent metastatic (RM) disease compared to the $75 \%$ (9 from 12) of CTC- patients who had stage IV or RM disease. Grade 3 disease and the presence of peritoneal and liver metastases were also more common in CTC+ patients.

For patients whose samples were collected after disease recurrence, average time to recurrence was shorter in CTC+ patients at 20.3 months (11 patients, range $9-38 \mathrm{~m}$ ) compared to 30.8 months (6 patients, range $5-95 \mathrm{~m}$ ) in CTC- patients. The hazard ratio (HR) for recurrence was 1.7 in favour of CTC- patients [p>0.05, 95\% confidence interval (Cl) 0.5-5.2].

More CTC- patients were alive at last follow-up compared to CTC+ patients. For patients who had died during follow-up, more CTC+ patients were deceased within 12 months after diagnosis with stage IV or RM disease compared to CTC- patients. The HR for survival was 3.3 favouring the CTCpatients [ $p>0.05,95 \% \mathrm{Cl} 0.7-16.2]$. The small sample size and short follow-up time limit the statistical analysis of these data. In terms of histopathologic parameters, there were more NEEC than EEC tumours [14/18 (78\%) vs $6 / 12(50 \%)]$ and uterine tumours larger than $5 \mathrm{~cm}[11 / 18(61 \%)$ vs $6 / 12(50 \%)]$ in the CTC+ patients compared to the CTC- patients. There were more CTC- patients with evidence of myometrial invasion (MMI) greater than 50\% [8/12 (67\%) vs 10/18 (56\%)]. Frequency of lymphovascular space invasion (LVSI) [6/12 (50\%) vs 8/18 (44\%) in CTC- vs CTC+] and cervical invasion [3/12 (25\%) vs 5/18 (28\%) in CTC- vs CTC+] was similar between the two groups.

\section{CTC molecular profiling}

From the 18 patients who were CTC+, 10 patients had CTCs with stathmin expression. Eight of these patients had all CTCs stain positive with stathmin while the remaining 2 patients had 2 from 4 cells stain positive for stathmin. This is detailed in Table 2.

One patient was stathmin negative. Seven patients did not have stathmin assessed due to supply restrictions; 3 patients with CTC 1, 1 patient with CTC 3 and patients with CTC 7, 8 and 22 . 


\section{Correlation of EpCAM and Stathmin IHC with CTC status}

The TIS for EpCAM and stathmin IHC was evaluated for 21 cases for which the blocks were available. Table 3 summarises the staining intensity of EPCAM and stathmin in the CTC+ and CTC- patient groups.

Eighteen from 21 cases (86\%) were EpCAM positive. Intense EpCAM TIS was found in more CTC+ compared to CTC- patients [12/15 (79.9\%) vs $4 / 6(66 \%)]$.

Sixteen from 21 cases (76\%) were stathmin positive. Intense stathmin TIS were also found in more CTC+ patients [upper quartile stathmin TIS in 7/15 (47\%) vs 1/6 (17\%) CTC+ vs CTC-].

From the 7 patients that were CTC stathmin positive and had tissue available, all had stathmin overexpression on IHC, compared to 1 CTC- patient.

\section{Longitudinal CTC assessment and clinical correlation}

Details of the longitudinal CTC values for both CTC+ and CTC negative (CTC-) patients and the clinical correlation are detailed in Table 2.

Of the $18 \mathrm{CTC}+$ patients, 12 were sampled pre and during first-line chemotherapy for metastatic EC and 1 patient had follow-up samples taken during clinical trial involvement (all marked * in Table 2). Of the other 5, 1 developed detectable CTCs during follow-up but did not have further treatment and the other 4 patients were CTC+ at baseline but died without further follow-up.

For the $13 \mathrm{CTC}+$ patients during treatment, 8 patients demonstrated changes in their CTC counts over time that were concordant with their clinical and radiological progress. Five from the 8 patients had positive baseline CTC counts that decreased during first-line chemotherapy and correlated with a partial response on imaging. One of these patients then had a CTC rise on $3^{\text {rd }}$ follow-up with disease progression and died. One patient was CTC+ at baseline with a further increase during chemotherapy and died. One patient was CTC- with stable disease during first-line chemotherapy but had increased CTCs post chemotherapy with disease progression and died. The clinical trial patient had disease progression pre-trial with a positive CTC value that became negative after one month on trial corresponding with a partial response on imaging. The other 5 from 13 CTC+ patients had changes in CTC counts that did not correlate with their clinical picture. For the 12 patients who were CTC- at baseline and in follow-up, 7 had a clinical and/or radiological picture that correlated with the CTC result, 1 had a discordant picture and 4 had only a single CTC assessment and evaluation of concordance was limited. This is also outlined in Table 2. 


\section{DISCUSSION}

Our study not only demonstrates the feasibility of CTC detection in EC on the CellSearch platform but importantly, of CTC molecular profiling with stathmin, which has potential utility across tumour types as a marker of PI3K pathway activity.

The PI3K/AKT/ mammalian target of rapamycin (mTOR) pathway is one of the most studied pathways in EC with aberrations including oncogenic PIK3CA mutations and PTEN loss of function. However, reproducible, predictive, time- and cost-efficient markers of PI3K pathway activation remain elusive. The finding of stathmin overexpression in this study is a novel one and is the first report in EC CTCs and in CTCs in general. The next challenge in translating stathmin into a usable biomarker is to correlate CTC stathmin positivity with PI3K pathway activity, to see whether CTC stathmin status could be used to predict response to agents targeting the PI3K/Akt/mTOR pathway. To this end, we assessed stathmin overexpression on FFPE tissue as this is a known prognostic marker in EC with evidence of predictive utility in response to taxanes. Our finding of stathmin overexpression on FFPE EC was 47\%, consistent with the literature reports of overexpression in between $27 \%$ and $57 \%$ of primary tumours $[21,30]$. Interestingly, CTC positivity was associated with higher stathmin IHC TIS, consistent with the prognostic association of stathmin overexpression and the worse clinical outcome of CTC+ patients here. Further work however is required to better define this relationship and may in fact be worthy of investigation across tumour types including breast and prostate cancer, where CTCs have already demonstrated prognostic utility and activity of the PI3K pathway is also well documented [31, 32].

CTC positivity in EC has also been demonstrated by Bogani et al [33] using the Janssen CellSearch platform. They reported positive CTCs in 2 from 28 (7\%) EC patients preoperatively, both having grade 3, stage IIIC, EEC. They also found an association with deep MMI and lymph node positivity. Of note, of the patients included in this study, 18 had stage I disease, 1 had stage II, 6 had stage III and 3 had stage IV disease. In contrast, we demonstrated CTC positivity in $60 \%$ of patients with stage IV or recurrent metastatic EC, both in EEC and NEEC. Patients with advanced EC were selected here, aiming to increase the detection of patients with CTC positivity that could then be followed longitudinally and have molecular profiling performed.

Furthermore, in a subset of patients receiving first-line chemotherapy for metastatic disease, we were able to demonstrate that longitudinal assessment of CTCs correlated with clinical outcome. Interestingly, there was a trend between CTC positivity and higher stage, grade 3 disease, NEEC histology, shorter time to recurrence and reduced survival.

There were also patients however, whose CTC follow-up did not correlate with their clinical course and a number of factors in our study that did not correlate with CTC positivity, including MMI, LVSI 
and cervical invasion, all being traditional parameters currently used to guide primary treatment post-surgery. This may reflect the limitations of these traditional pathologic factors in guiding primary treatment or limitations in CTC evaluation and our sample size.

This study demonstrates the presence of CTCS in EC using the EpCAM based CellSearch platform as well as early clinical correlation patterns. Important to the utility of the CellSearch platform is the presence of EPCAM and overexpression was reported in $86 \%$ of the archival FFPE tissue here, consistent with the published literature of moderate to intense EpCAM overexpression in $80-88 \%$ $[10,34]$ of EC specimens. However, it is known that down-regulation of EpCAM occurs when cancers and CTCs undergo epithelial-mesenchymal transition (EMT) and develop a more invasive phenotype with metastatic potential. In a comparison of EPCAM expression on CTCs versus FFPE tissue and other benign disease, EPCAM expression was demonstrated to be 10 -fold lower on CTCs compared to primary or metastatic tissue [35]. Despite such potential limitations, an EpCAM detection system may still be preferred in EC, particularly with its high rate of EDCAM overexpression, though other techniques now warrant investigation to determine the optimum method for this cancer type and whether a certain platform is better for enumeration or isolation for MP. This may include other EpCAM based techniques such as the Gilupi nanodetector [36], or techniques based on physical properties such as the ISET (isolation by size of epithelial tumour cells) system [37, 38], dielectrophoretic field flow fractionation (depFFF) methods [39, 40], and Imagestream (Amnis) that combines flow cytometry and fluorescent microscopy in a single platform [41]. In terms of CTC MP, although the use of an antibody within the fourth channel on the CellSearch platform is the most time-efficient, it only allows analysis for a single antibody per blood sample and each antibody must be appropriately validated for use on CTCs. Further techniques have been described to extract CTCS from the CellSearch magnetic cartridge and perform further $\operatorname{MP}[3,5,6]$.

Although the small patient number here limits statistical power, correlation of CTC stathmin positivity with outcomes with both chemotherapy and PI3K pathway targeted agents in EC and other tumours is worthy of further exploration. The ability to detect stathmin on CTCs, the reproducibility of staining and evidence as a marker of PI3K activation [26] make stathmin an attractive choice of antibody.

Longitudinal tissue analysis of EPCAM and PI3K alterations and mapping CTC molecular analysis could provide strong evidence for using CTCs and their MP as a so-called 'liquid biopsy' to predict response to standard chemotherapy and molecularly targeted agents (MTAs) for each patient. If validated in larger studies, longitudinal evaluation of CTCs, stathmin expression and correlation with treatment outcome may provide the first predictive biomarker for treatment response in EC and act as a surrogate marker for survival in those patients who are CTC+. CTCs and their stathmin 
expression along with further MP could be incorporated into clinical trials that assess PI3K pathway targeting agents and other MTAs with the potential of better streamlining clinical trial and drug development. 


\section{REFERENCES}

1. Cancer Statistics Registrations, England (Series MB1) - No.43. 2012; Available from: http://www.ons.gov.uk/ons/rel/vsob1/cancer-statistics-registrations--england--seriesmb1-/index.html.

2. Allard, W.J., et al., Tumor cells circulate in the peripheral blood of all major carcinomas but not in healthy subjects or patients with nonmalignant diseases. Clinical cancer research : an official journal of the American Association for Cancer Research, 2004. 10(20): p. 6897-904.

3. Attard, G., et al., Characterization of ERG, AR and PTEN gene status in circulating tumor cells from patients with castration-resistant prostate cancer. Cancer research, 2009. 69(7): p. 2912-8.

4. Gasch, C., et al., Heterogeneity of epidermal growth factor receptor status and mutations of KRAS/PIK3CA in circulating tumor cells of patients with colorectal cancer. Clinical chemistry, 2013. 59(1): p. 252-60.

5. Marchetti, A., et al., Assessment of EGFR Mutations in Circulating Tumor Cell Preparations from NSCLC Patients by Next Generation Sequencing: Toward a RealTime Liquid Biopsy for Treatment. PLoS One, 2014. 9(8): p. e103883.

6. Shaffer, D.R., et al., Circulating tumor cell analysis in patients with progressive castration-resistant prostate cancer. Clinical cancer research : an official journal of the American Association for Cancer Research, 2007. 13(7): p. 2023-9.

7. de Bono, J.S., et al., Circulating tumor cells predict survival benefit from treatment in metastatic castration-resistant prostate cancer. Clinical cancer research : an official journal of the American Association for Cancer Research, 2008. 14(19): p. 6302-9.

8. Bidard, F.C., et al., Clinical validity of circulating tumour cells in patients with metastatic breast cancer: a pooled analysis of individual patient data. The lancet oncology, 2014. 15(4): p. 406-14.

9. Cohen, S.J., et al., Relationship of circulating tumor cells to tumor response, progression-free survival, and overall survival in patients with metastatic colorectal cancer. Journal of clinical oncology : official journal of the American Society of Clinical Oncology, 2008. 26(19): p. 3213-21.

10. Went, P., Dirnhofer, S., Schopf, D., Moch, H. and Spizzo, G., Expression and Prognostic Significance of EpCAM. Journal of Cancer Molecules, 2008. 3(6): p. 6.

11. Rubin, C.I. and G.F. Atweh, The role of stathmin in the regulation of the cell cycle. Journal of cellular biochemistry, 2004. 93(2): p. 242-50.

12. Trovik, J., et al., Stathmin overexpression identifies high-risk patients and lymph node metastasis in endometrial cancer. Clinical cancer research : an official journal of the American Association for Cancer Research, 2011. 17(10): p. 3368-77.

13. Baquero, M.T., et al., Stathmin expression and its relationship to microtubuleassociated protein tau and outcome in breast cancer. Cancer, 2012. 118(19): p. 46609.

14. Friedrich, B., et al., Differentiation-stage specific expression of oncoprotein 18 in human and rat prostatic adenocarcinoma. The Prostate, 1995. 27(2): p. 102-9.

15. Golouh, R., et al., The prognostic value of Stathmin-1, S100A2, and SYK proteins in ER-positive primary breast cancer patients treated with adjuvant tamoxifen monotherapy: an immunohistochemical study. Breast cancer research and treatment, 2008. 110(2): p. 317-26.

16. Ke, B., et al., Overexpression of stathmin 1 is associated with poor prognosis of patients with gastric cancer. Tumour biology: the journal of the International Society for Oncodevelopmental Biology and Medicine, 2013. 34(5): p. 3137-45. 
17. Kouzu, Y., et al., Overexpression of stathmin in oral squamous-cell carcinoma: correlation with tumour progression and poor prognosis. British journal of cancer, 2006. 94(5): p. 717-23.

18. Lin, W.C., et al., Expression of stathmin in localized upper urinary tract urothelial carcinoma: correlations with prognosis. Urology, 2009. 74(6): p. 1264-9.

19. Salvesen, H.B., et al., Integrated genomic profiling of endometrial carcinoma associates aggressive tumors with indicators of PI3 kinase activation. Proceedings of the National Academy of Sciences of the United States of America, 2009. 106(12): p. 4834-9.

20. Su, D., et al., Stathmin and tubulin expression and survival of ovarian cancer patients receiving platinum treatment with and without paclitaxel. Cancer, 2009. 115(11): p. 2453-63.

21. Trovik, J., et al., Stathmin is superior to AKT and phospho-AKT staining for the detection of phosphoinositide 3-kinase activation and aggressive endometrial cancer. Histopathology, 2010. 57(4): p. 641-6.

22. Xi, W., et al., Expression of stathmin/op18 as a significant prognostic factor for cervical carcinoma patients. Journal of cancer research and clinical oncology, 2009. 135(6): p. 837-46.

23. Alli, E., et al., Effect of stathmin on the sensitivity to antimicrotubule drugs in human breast cancer. Cancer research, 2002. 62(23): p. 6864-9.

24. Werner, H.M., et al., Stathmin protein level, a potential predictive marker for taxane treatment response in endometrial cancer. PloS one, 2014. 9(2): p. e90141.

25. Werner, H.M.T., J.; Wik, E.; Akslen, L.A.; Salvesen, H.B., Abstract 3158: Stathmin expression predicts response to taxanes in metastatic endometrial cancer. Cancer research, 2011. 71(8): p. suppl.1; abstr. 3158.

26. Saal, L.H., et al., Poor prognosis in carcinoma is associated with a gene expression signature of aberrant PTEN tumor suppressor pathway activity. Proceedings of the National Academy of Sciences of the United States of America, 2007. 104(18): p. 7564-9.

27. Engelsen, I.B., et al., Pathologic expression of p53 or p16 in preoperative curettage specimens identifies high-risk endometrial carcinomas. American journal of obstetrics and gynecology, 2006. 195(4): p. 979-86.

28. Spizzo, G., et al., EpCAM expression in primary tumour tissues and metastases: an immunohistochemical analysis. Journal of clinical pathology, 2011. 64(5): p. 415-20.

29. Salvesen, H.B., S. Das, and L.A. Akslen, Loss of nuclear p16 protein expression is not associated with promoter methylation but defines a subgroup of aggressive endometrial carcinomas with poor prognosis. Clinical cancer research : an official journal of the American Association for Cancer Research, 2000. 6(1): p. 153-9.

30. Vandenput, I., et al., Evolution in endometrial cancer: evidence from an immunohistochemical study. International journal of gynecological cancer : official journal of the International Gynecological Cancer Society, 2011. 21(2): p. 316-22.

31. Baselga, J., Targeting the phosphoinositide-3 (PI3) kinase pathway in breast cancer. Oncologist, 2011. 16 Suppl 1: p. 12-9.

32. Majumder, P.K. and W.R. Sellers, Akt-regulated pathways in prostate cancer. Oncogene, 2005. 24(50): p. 7465-74.

33. Bogani, G., et al., Detection of circulating tumor cells in high-risk endometrial cancer. Anticancer Res, 2015. 35(2): p. 683-7.

34. Spizzo, G., et al., Overexpression of epithelial cell adhesion molecule (Ep-CAM) is an independent prognostic marker for reduced survival of patients with epithelial ovarian cancer. Gynecologic oncology, 2006. 103(2): p. 483-8. 
35. Rao, C.G., et al., Expression of epithelial cell adhesion molecule in carcinoma cells present in blood and primary and metastatic tumors. International journal of oncology, 2005. 27(1): p. 49-57.

36. Saucedo-Zeni, N., et al., A novel method for the in vivo isolation of circulating tumor cells from peripheral blood of cancer patients using a functionalized and structured medical wire. International journal of oncology, 2012. 41(4): p. 1241-50.

37. Vona, G., et al., Isolation by size of epithelial tumor cells : a new method for the immunomorphological and molecular characterization of circulatingtumor cells. The American journal of pathology, 2000. 156(1): p. 57-63.

38. Paterlini-Brechot, P. and N.L. Benali, Circulating tumor cells (CTC) detection: clinical impact and future directions. Cancer letters, 2007. 253(2): p. 180-204.

39. Gascoyne, P.R., et al., Isolation of rare cells from cell mixtures by dielectrophoresis. Electrophoresis, 2009. 30(8): p. 1388-98.

40. Fuchs, A.B., et al., Electronic sorting and recovery of single live cells from microlitre sized samples. Lab on a chip, 2006. 6(1): p. 121-6.

41. Lopez-Riquelme, N., et al., Imaging cytometry for counting circulating tumor cells: comparative analysis of the CellSearch vs ImageStream systems. APMIS : acta pathologica, microbiologica, et immunologica Scandinavica, 2013. 121(12): p. 113943. 
TABLES

Table 1: Differences in treatment and clinical course between CTC+ and CTC- patients

\begin{tabular}{|c|c|c|}
\hline & CTC- (\%), n=12 & $\mathrm{CTC}+(\%), \mathrm{n}=18$ \\
\hline Mean age in years (range) & $66(49-83)$ & $66(55-79)$ \\
\hline $\begin{array}{l}\text { Sites of metastases } \\
\text { Peritoneal, LN, Liver }\end{array}$ & $4(44), 7(77), 1(8)$ & $13(72), 15(83), 5(27)$ \\
\hline Grade 3 disease & $7(58)$ & $15(83)$ \\
\hline $\begin{array}{l}\text { Survival status with stage IV } \\
\text { disease based on } \mathrm{f} / \mathrm{u} \text { time from } \\
\text { diagnosis of metastases }\end{array}$ & $\begin{array}{l}2 \text { from } 9 \text { died at }>12 \mathrm{~m} \\
\quad(\text { mean } 13 \mathrm{~m} \text { ) } \\
5 \text { alive at } \leq 12 \mathrm{~m} \mathrm{f} / \mathrm{u} \\
2 \text { alive }>12 \mathrm{~m} \mathrm{f} / \mathrm{u} \\
\text { (mean } 15 \mathrm{~m} \mathrm{f} / \mathrm{u} \text { time) }\end{array}$ & $\begin{array}{l}6 \text { from } 18 \text { died } \leq 12 \mathrm{~m} \\
2 \text { died }>12 \mathrm{~m} \\
\quad \text { (mean } 9 \mathrm{~m} \text { for these } 8 \mathrm{pts} \text { ) } \\
9 \text { alive } \leq 12 \mathrm{~m} \mathrm{f} / \mathrm{u} \\
1 \text { alive }>12 \mathrm{~m} \mathrm{f} / \mathrm{u} \\
\quad \text { (mean } 8.5 \mathrm{~m} \mathrm{f} / \mathrm{u} \text { time) }\end{array}$ \\
\hline
\end{tabular}

LN: Iymph node, RM: recurrent metastatic, pts: patients, f/u: follow-up 
Table 2: Clinical and CTC Correlation for patients with longitudinal CTC assessment: CTC positive (left) and CTC negative (right)

\begin{tabular}{|c|c|c|c|c|c|c|c|}
\hline Pt & $\begin{array}{l}\text { Baseline } \\
\text { CTC value } \\
(\mathrm{S}+)\end{array}$ & $\begin{array}{l}\text { Longitudinal } \\
\text { CTC values } \\
\text { (S+) } \\
\text { [number of } \\
\text { collections] }\end{array}$ & Clinical picture & Pt & $\begin{array}{l}\text { Baseline } \\
\text { CTC value } \\
(\mathrm{S}+)\end{array}$ & $\begin{array}{l}\text { Longitudinal } \\
\text { CTC values } \\
(\mathrm{S}+) \text { [number } \\
\text { of collections] }\end{array}$ & Clinical picture \\
\hline \multicolumn{8}{|c|}{ Patients with concordant CTC value and clinical picture } \\
\hline $\begin{array}{l}3, \\
7, \\
8, \\
17\end{array}$ & $\begin{array}{l}7 \text { (ne) } \\
1 \text { (ne) } \\
22 \text { (ne) } \\
8 \text { (ne) }\end{array}$ & & $\begin{array}{l}\text { Only } 1 \text { sample } \\
\text { taken prior to PD \& } \\
\text { deceased }\end{array}$ & 4 & 0 & $0[\times 3]$ & $\begin{array}{l}\text { LA disease (FIGO } \\
\text { IIIB) } \\
\text { DF post RT }\end{array}$ \\
\hline 6* & 172 (ne) & $3878(0)$ & $\begin{array}{l}\text { PD during chemo \& } \\
\text { deceased }\end{array}$ & 20 & 0 & 0 & $\begin{array}{l}\text { SD on hormonal } \\
\text { treatment }\end{array}$ \\
\hline 9* & $2(2)$ & $\begin{array}{l}0 \\
2[\times 2]\end{array}$ & $\begin{array}{l}\text { PR during 1stline } \\
\text { chemo } \\
\text { PD 4m post chemo } \\
\text { \& deceased }\end{array}$ & 21 & 0 & 0 & $\begin{array}{l}\text { SD mid 1stline } \\
\text { chemo }\end{array}$ \\
\hline $\begin{array}{l}12 \\
*\end{array}$ & 0 & $\begin{array}{l}0 \\
3 \text { (ne) }\end{array}$ & $\begin{array}{l}\text { SD during 1stline } \\
\text { chemo } \\
\text { PD } 4 \text { m post chemo } \\
\text { \& deceased }\end{array}$ & 23 & 0 & $0[x 2]$ & $\begin{array}{l}\text { Local disease } \\
\text { (FIGO IB) } \\
\text { DF post chemo } \\
\text { \& RT }\end{array}$ \\
\hline $\begin{array}{l}13 \\
*\end{array}$ & $1(1)$ & 0 & $\begin{array}{l}\text { PR during 1stline } \\
\text { chemo }\end{array}$ & 29 & 0 & & $\begin{array}{l}\text { LA disease (FIGO } \\
\text { IIIC) } \\
\text { DF mid chemo }\end{array}$ \\
\hline 14 & 0 & $1(1)$ & $\begin{array}{l}\text { PD during } \mathrm{f} / \mathrm{u} \text { (too } \\
\text { unwell for 1stline } \\
\text { chemo) }\end{array}$ & 30 & 0 & 0 & $\begin{array}{l}\text { SD post 1stline } \\
\text { chemo }\end{array}$ \\
\hline $\begin{array}{l}24 \\
* \\
\end{array}$ & $2(2)$ & $1(1)$ & $\begin{array}{l}\text { PR during 1stline } \\
\text { chemo }\end{array}$ & 33 & 0 & 0 & $\begin{array}{l}\text { SD mid 1stline } \\
\text { chemo }\end{array}$ \\
\hline $\begin{array}{l}26 \\
*\end{array}$ & $4(2)$ & $1(1)$ & $\begin{array}{l}\text { PR during 1stline } \\
\text { chemo }\end{array}$ & & & & \\
\hline $\begin{array}{l}27 \\
*\end{array}$ & $4(2)$ & $0[\mathrm{x} 2]$ & $\begin{array}{l}\text { PR during 1stline } \\
\text { chemo }\end{array}$ & & & & \\
\hline $\begin{array}{l}31 \\
*\end{array}$ & 0 & $\begin{array}{l}1(1) \\
0\end{array}$ & $\begin{array}{l}\text { PD pre-clinical trial } \\
\text { PR post } \mathrm{C} 1 \text { clinical } \\
\text { trial }\end{array}$ & & & & \\
\hline \multicolumn{8}{|c|}{ Patients that did not have concordant CTC value and clinical picture } \\
\hline $\begin{array}{l}11 \\
*\end{array}$ & 0 & $\begin{array}{l}2(2) \\
0[\times 2]\end{array}$ & $\begin{array}{l}\text { SD post 1stline } \\
\text { chemo } \\
\text { SD, then PD } 1 \mathrm{~m} \\
\text { later \& deceased }\end{array}$ & 1 & 0 & $\mathrm{H}$ & $\begin{array}{l}\text { Pre 1stline } \\
\text { chemo } \\
\text { No f/u }\end{array}$ \\
\hline $\begin{array}{l}15 \\
*\end{array}$ & 0 & $\begin{array}{l}1(1) \\
0\end{array}$ & $\begin{array}{l}\text { SD post chemo } \\
\text { PD }\end{array}$ & 2 & 0 & - & PD in brain \\
\hline $\begin{array}{l}22 \\
*\end{array}$ & $2(2)$ & 0 & PD \& deceased & 19 & 0 & $0[\mathrm{x} 2]$ & PD \\
\hline $\begin{array}{l}25 \\
*\end{array}$ & 0 & 1 (ne) & SD & 34 & 0 & - & PD in lung \\
\hline $\begin{array}{l}28 \\
*\end{array}$ & 0 & $\begin{array}{l}1 \text { (ne) } \\
0\end{array}$ & $\begin{array}{l}\text { PR at C4 1stline } \\
\text { chemo } \\
\text { Ongoing PR at EOT } \\
\text { scan }\end{array}$ & 35 & 0 & - & $\begin{array}{l}\text { Pre 1stline } \\
\text { chemo } \\
\text { No f/u }\end{array}$ \\
\hline
\end{tabular}

S: stathmin, PD: progressive disease, LA: locally advanced, FIGO: International Federation of Gynaecology and Obstetrics, PR: partial response, SD: stable disease, DF: disease free *denotes 13 patients sample during first-line chemotherapy or clinical trial involvement 
Table 3: EpCAM and Stathmin IHC results relative to CTC Status

\begin{tabular}{|l|l|l|}
\hline & CTC positive; $n=15(\%)$ & CTC negative; $n=6(\%)$ \\
\hline EpCAM TIS & & \\
Intense & $12(79.9)$ & $4(66)$ \\
Moderate & $1(6.7)$ & $1(17)$ \\
Weak & $1(6.7)$ & $1(17)$ \\
No staining & $1(6.7)$ & 0 \\
\hline Stathmin TIS [score] & & \\
Upper quartile & $7(47)$ & $1(17)$ \\
Intense [9] & $1(6.7)$ & 0 \\
Moderate [ 4 or 6] & $11[5,6](73.3[33.3,40])$ & $4[3,1](66[50,16])$ \\
None/Weak [<4] & $1(6.7)$ & $1(17)$ \\
Not available & $2(13.3)$ & $1(17)$ \\
\hline
\end{tabular}

EpCAM: epithelial cell adhesion molecule, IHC: immunohistochemistry, TIS: tumour immunostaining score 
SUPPLEMENTARY MATERIAL

On-board dewax and rehydration were performed followed by epitope retrieval by either heatinduced (HIER with ER2, EDTA-based, Cat No AR9961) for stathmin IHC or enzymatic digestion (with Enzyme 1 diluted 1/2000, Bond Enzyme Pretreatment Kit, Cat No AR9551) for EpCAM IHC. Peroxide block provided in the Bond Polymer Refine Detection Kit (Cat No DS9800) was then applied followed by the primary antibody for $30 \mathrm{~min}$ or $15 \mathrm{~min}$ for stathmin and EPCAM respectively. This was followed by a rabbit anti-mouse post primary antibody for $20 \mathrm{~min}$ and $8 \mathrm{~min}$ and goat anti-rabbit horseradish peroxidase conjugated polymer (components of DS9800) for $20 \mathrm{~min}$ and $8 \mathrm{~min}$ for stathmin and EPCAM IHC respectively. Antigens were visualised with the substrate chromogen 3,3'Diaminobenzidine tetrahydrochloride (DAB, Cat No 9800) and Bond DAB Enhancer (Cat No AR9432) was added. Slides were counterstained with haematoxylin (component of DS9800) and mounted. In addition to the standard protocol, $10 \%$ goat serum was used after stathmin antibody application for those slides sectioned from surgical resection samples.

Table 1: Staining Protocols for EPCAM, Stathmin and p70S6kinase

\begin{tabular}{|c|c|c|c|c|c|c|c|c|}
\hline Step & EpCAM & & $\begin{array}{l}\text { Stathmin } \\
\text { B }\end{array}$ & & $\begin{array}{l}\text { Stathmin } \\
\mathrm{S}\end{array}$ & & $\begin{array}{l}\text { P70S6 } \\
\text { kinase } \\
B / S\end{array}$ & \\
\hline Part 1 & $\begin{array}{l}\text { Time } \\
\text { (min) }\end{array}$ & $\begin{array}{l}\text { Temp } \\
\left({ }^{\circ} \mathrm{C}\right)\end{array}$ & Time & Temp & Time & Temp & Time & Temp \\
\hline Bake & 60 & 60 & 60 & 60 & 60 & 60 & 60 & 60 \\
\hline $\begin{array}{l}\text { Bond dewax } \\
\text { solution }\end{array}$ & $\begin{array}{l}0.5 \times 1 \\
0 \times 1 \\
0 \times 1 \\
\end{array}$ & $\begin{array}{l}72 \\
72 \\
\text { Room } \\
\end{array}$ & $\begin{array}{l}0.5 \times 1 \\
0 \times 1 \\
0 \times 1 \\
\end{array}$ & $\begin{array}{l}72 \\
72 \\
\text { Room } \\
\end{array}$ & $\begin{array}{l}0.5 \times 1 \\
0 \times 1 \\
0 \times 1 \\
\end{array}$ & $\begin{array}{l}72 \\
72 \\
\text { Room } \\
\end{array}$ & $\begin{array}{l}0.5 \times 1 \\
0 \times 1 \\
0 \times 1 \\
\end{array}$ & $\begin{array}{l}72 \\
72 \\
\text { Room } \\
\end{array}$ \\
\hline Alcohol & $0 \times 3$ & Room & $0 \times 3$ & Room & $0 \times 3$ & Room & $0 \times 3$ & Room \\
\hline BWS & $\begin{array}{l}0 \times 2 \\
5 \times 1 \\
\end{array}$ & Room & $\begin{array}{l}0 \times 2 \\
5 \times 1 \\
\end{array}$ & Room & $\begin{array}{l}0 \times 2 \\
5 \times 1\end{array}$ & Room & $\begin{array}{l}0 \times 2 \\
5 \times 1 \\
\end{array}$ & Room \\
\hline $\begin{array}{l}{ }^{*} \text { ER2 } \\
\text { ER2 } \\
\text { ER2 } \\
\text { BWS } \\
\text { BWS } \\
\text { OR } \\
\text { *Enzyme } 1 \\
\text { BWS }\end{array}$ & $\begin{array}{l}10 \\
0 \times 3\end{array}$ & $\begin{array}{l}37 \\
\text { Room }\end{array}$ & $\begin{array}{l}0 \times 2 \\
20 \\
12 \\
0 \times 3 \\
3 \\
-\end{array}$ & $\begin{array}{l}\text { Room } \\
100 \\
\text { Room } \\
35 \\
\text { Room } \\
-\end{array}$ & $\begin{array}{l}0 \times 2 \\
20 \\
12 \\
0 \times 3 \\
3 \\
-\end{array}$ & $\begin{array}{l}\text { Room } \\
100 \\
\text { Room } \\
35 \\
\text { Room } \\
-\end{array}$ & $\begin{array}{l}0 \times 2 \\
30 / 40 \\
12 \\
0 \times 3 \\
3 \\
-\end{array}$ & $\begin{array}{l}\text { Room } \\
100 \\
\text { Room } \\
35 \\
\text { Room } \\
-\end{array}$ \\
\hline $\begin{array}{l}\text { Peroxide } \\
\text { block }\end{array}$ & 5 & Room & 5 & Room & 5 & Room & 5 & Room \\
\hline BWS & $0 \times 3$ & Room & $0 \times 3$ & Room & $0 \times 3$ & Room & $0 \times 3$ & Room \\
\hline $1^{\circ} \mathrm{Ab}$ & 15 & Room & 30 & Room & 30 & Room & $30 / 60$ & Room \\
\hline BWS & $2 \times 3$ & Room & $0 \times 3$ & Room & $0 \times 3$ & Room & $0 \times 3$ & Room \\
\hline $\begin{array}{l}10 \% \text { goat } \\
\text { serum }\end{array}$ & - & - & - & - & 20 & Room & - & - \\
\hline BWS & - & - & - & - & $0 \times 3$ & Room & $0 \times 3$ & Room \\
\hline Post- $1^{\circ} \mathrm{Ab}$ & 8 & Room & 20 & Room & 20 & Room & 20 & Room \\
\hline
\end{tabular}




\begin{tabular}{|l|l|l|l|l|l|l|l|l|}
\hline BWS & $2 \times 3$ & Room & $2 \times 3$ & Room & $2 \times 3$ & Room & $2 \times 3$ & Room \\
\hline Polymer & 8 & Room & 20 & Room & 20 & Room & 20 & Room \\
\hline BWS & $2 \times 2$ & Room & $2 \times 2$ & Room & $2 \times 2$ & Room & $2 \times 2$ & Room \\
\hline DW & 0 & Room & 0 & Room & 0 & Room & 0 & Room \\
\hline $\begin{array}{l}\text { Mixed DAB } \\
\text { refine }\end{array}$ & $0 \& 10$ & Room & $0 \& 10$ & Room & $0 \& 10$ & Room & $0 \& 10$ & Room \\
\hline DW & $0 \times 3$ & Room & $0 \times 3$ & Room & $0 \times 3$ & Room & $0 \times 3$ & Room \\
\hline $\begin{array}{l}\text { Bond DAB } \\
\text { enhancer }\end{array}$ & 5 & room & 5 & Room & 5 & Room & 5 & Room \\
\hline BWS & $0 \times 3$ & Room & $0 \times 3$ & Room & $0 \times 3$ & Room & $0 \times 3$ & Room \\
\hline Haematoxylin & 1 & Room & 1 & Room & 1 & Room & 1 & Room \\
\hline DW & 0 & Room & 0 & Room & 0 & Room & 0 & Room \\
\hline BWS & 0 & Room & 0 & Room & 0 & Room & 0 & Room \\
\hline DW & 0 & Room & 0 & Room & 0 & Room & 0 & Room \\
\hline
\end{tabular}

Time 0 indicates a wash, as opposed to incubation $\mathrm{X} 3$ indicates the wash occurred 3 times

BS2: bond solution 2, BWS: bond wash solution, DW: deionised water,

B: biopsy specimen, S: surgical resection specimen

*This row indicates the epitope retrieval method; either with the ER2 HIER technique or enzymatic epitope retrieval technique with Enzyme 1. 